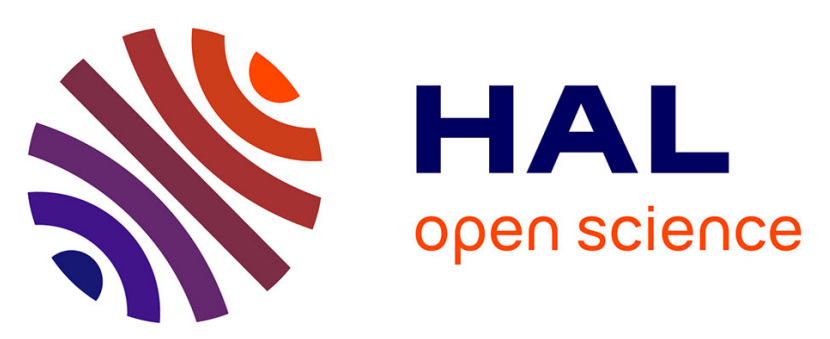

\title{
Improving fluency of young readers: introducing a Karaoke to learn how to breath during a Reading-while-Listening task
}

Erika Godde, Gérard Bailly, David Escudero, Marie-Line Bosse, Maryse Bianco, Coriandre Emmanuel Vilain

\section{To cite this version:}

Erika Godde, Gérard Bailly, David Escudero, Marie-Line Bosse, Maryse Bianco, et al.. Improving fluency of young readers: introducing a Karaoke to learn how to breath during a Reading-whileListening task. SLaTE 2017 - 7th ISCA Workshop on Speech and Language Technology in Education, Aug 2017, Stockholm, Sweden. pp.127-131, 10.21437/SLaTE.2017-22 . hal-01575223

\section{HAL Id: hal-01575223 \\ https://hal.science/hal-01575223}

Submitted on 18 Aug 2017

HAL is a multi-disciplinary open access archive for the deposit and dissemination of scientific research documents, whether they are published or not. The documents may come from teaching and research institutions in France or abroad, or from public or private research centers.
L'archive ouverte pluridisciplinaire $\mathbf{H A L}$, est destinée au dépôt et à la diffusion de documents scientifiques de niveau recherche, publiés ou non, émanant des établissements d'enseignement et de recherche français ou étrangers, des laboratoires publics ou privés. 


\title{
Improving fluency of young readers: introducing a Karaoke to learn how to breath during a Reading-while-Listening task
}

\author{
Erika Godde $^{1}$, Gérard Bailly ${ }^{1}$, David Escudero ${ }^{2,1}$, Marie-Line Bosse $^{3}$, Maryse Bianco $^{4}$, Coriandre \\ Vilain $^{1}$
}

${ }^{1}$ GIPSA-Lab, Univ. Grenoble Alpes \& CNRS, F-38000 Grenoble, France

${ }^{2}$ Department of Computer Science, Univ. of Valladolid, Spain

${ }^{3}$ LPNC, Univ. Grenoble Alpes \& CNRS, F-38000 Grenoble, France

${ }^{4}$ LSE, Univ. Grenoble Alpes, F-38000 Grenoble, France

\{erika.godde, gerard.bailly, coriandre.vilain\}@gipsa-lab.fr, descudereinfor.uva.es

\{marie-line.bosse, maryse.bianco\}@univ-grenoble-alpes.fr

\begin{abstract}
We evaluate here an original method for implicitly providing breathing guidance to young readers during a Reading-whileListening task. Close-shadowing is supplemented by a Karaoke system that enlightens not only the word - as it is jointly spelled by the pre-recorded expert reader and the learner - but also the current and next breath groups. We compare here the impact of two enlightening conditions - i.e. word-only vs. word and breath group - on fluency and comprehension.

Index Terms: reading, reading-while-listening, breathing, fluency, children
\end{abstract}

\section{Introduction}

Fluent reading requires the setting up and coordination of multiple processes [1]: visual decoding of letters, letter-tosound mapping and phonological processing, linguistic analysis, breathing and speech articulation, etc. The setting-up of this complex neural system is thus progressive. Fluency in reading is acquired through several skills: accuracy, automaticity, grouping and expressivity [2]. We are here interested in the grouping skill. During the two first years of school, learning to read is mostly focused on accuracy and automacy. Many pupils think then that a good reader is a fast reader, regardless of understanding or being understood. During the third grade, children try to have a more listener-oriented reading. The grouping of words into meaningful units is one of the first challenge of this perspective taking. Well-formed prosody - i.e. regular breathing rhythm and pause patterning - should be thus planned according to the text structure.

The aim of our project is to help young readers in acquiring grouping skills by enhancing their breathing patterns while reading. For this purpose, we propose to use an audio-visual enhanced Reading-while-Listening paradigm (RwL) with closeshadowing: the young readers are instructed to shadow skilled readers while the current spelled units - namely characters, phones, syllables, words, phrases, breath groups, etc - are synchronously enlighten as in Karaoke. We here test if the synchronous enlightening of the breath groups of the skilled reader influences breathing patterns of young readers... and further help them to plan meaningful word groupings. This study aims to answer 3 main questions:

Close-shadowing. Are children able to perform closeshadowing in this audiovisual RwL condition?
Implicit monitoring of breathing patterns. Does the enlightening of breath groups by Karaoke impact children's breathing patterns?

Impact on fluency and comprehension. Does this exposure to enhanced RwL have an impact on text comprehension and further autonomous reading?

\section{State of the art}

According to Rasinski et al [2], there are four levels of fluency:

Accuracy: the reader is in a decoding phase. He's reading word by word, even syllable by syllable at slow rates.

Automaticity: the reader reads entire words and begins to read primarily in $2 / 3$ words grouping regardless of the context. He can read slowly or fast.

Grouping: the reader groups words in an appropriate phrasing at an appropriate rate.

Expressivity: the reader makes large and meaningful phrase groups with expressive interpretation.

Rasinsky et al. also point out that reading fluency does not only consist in acquiring automaticy and speed but also linguistic and paralinguistic prosody, i.e. the last two stages. Prosody aims at easing linguistic analysis but also adds meaning to the text i.e. "how the speaker feels about what he says" [3]. Rasinsky finally notes that speed is often an obstacle to prosody planning. Moreover, Arcand et al [4] recently showed that comprehension is more correlated to prosody than to speed and accuracy, notably with young readers. A recent study of Alvarez et al [5] also linked comprehension and prosody - particularly pause distribution - with children of 3rd and 6th grades.

\subsection{Enhancing grouping by working on breathing}

One of the functions of prosody is to ease segmentation and hierarchy, notably by translating punctuation into speech [6]. This means marking inter- and intra-sentence boundaries by pauses. Schwanenflugel et al showed that there are significant differences between intra- and inter-sentence pause lengths, as well as variability of their respective distributions among young readers, depending on their reading skills. The more skilled readers have shorter pauses and less variability. While inter-sentence pauses are based on punctuation and are therefore easily located by the children, intra-sentence pauses are based on syntax and necessitate an incremental processing of text that is often 
beyond children's capabilities. Arcand et al [4] showed that comprehension is negatively correlated to inappropriate pauses. Several studies on adults $[7,8,9]$ also separate the pauses in two categories: breathing pauses and non-breathing pauses. Breathing pauses are longer and located at major syntactic boundaries. Appropriate location of inhalations is thus both beneficial to the speaker (take air regularly and avoid out-of-breaths) and the listener (ease linguistic analysis). Grosjean et al [8] showed that when the readers read faster than normal, the need to breathe takes over and controls the occurrence of pauses, inducing a change in word grouping and making breathing pauses shorter, a phenomenon we experienced with young readers.

\subsubsection{Reading-while-Listening}

Reading-while-Listening (RwL) has long proved to be a good way to enhance fluency. In this method, the learner listens to someone else reading a text and simultaneously follows his performance in the printed text. Then he tries to imitate the skilled reader he just heard. This method quickly improves reading speed and accuracy $[10,11]$. In our study, we used an enhanced version of RwL using both audio and visual stimuli. This Karaoke method has been used by few teams to improve fluency. Biggs et al [12] used a singing Karaoke with middle school struggling readers during 9 weeks, 3 times a week. The children were very motivated by the exercise of repeated reading in this condition. Their fluency reading scores were remarkably improved during this session. Gerbier et al [13] used a reading Karaoke to improve word memorization and eye movement while reading, with 6 th grade pupils. They showed that the Karaoke improved attention, gaze strategy and semantic recall.

\subsubsection{Close-shadowing}

In the Gerbier et al experiment, the subject had to read simultaneously with the karaoke, trying to synchronize his speech to the tutor's one. We here hope that the children imitating the karaoke tutor will also be synchronizing their breath with the skilled reader, and so making meaningful breath group. To our knowledge, this close-shadowing has not been studied with children. Stenton [14] augmented L2 listening perception and spoken production through Karaoke with an emphasis on lexical stress visual annotation. But subsequent spontaneous conversation did not confirm the idea of improved oral production. Bailly et al [15] studied close-shadowing with adults and the respiratory shadowing while reading with adults too. They show that, with adult readers, reading rates tend to adapt to each other depending on the degree of involvement in the joint action. More recently, shadowing have been proved useful to improve prosody of Japanese learners of English [16].

\subsection{Monitoring breathing}

To study the breathing shadowing, we needed to record breathing while Karaoke-enhanced RwL. As the subject were children in a classroom context, we used a system that is light and easy to use and transport. Several studies used respiratory belts on reading adults $[9,15,17]$. We used here two belts and a Biopac $^{\circledR}$ system to acquire synchronized audio and respiratory data (see 3).

\subsection{Assessing understanding and fluency}

In order to assess the impact of the karaoke RwL on the pupils' reading skills, we chose to use a particular maze test. Maze tests are proved to be good indicators of reading skills, particularly

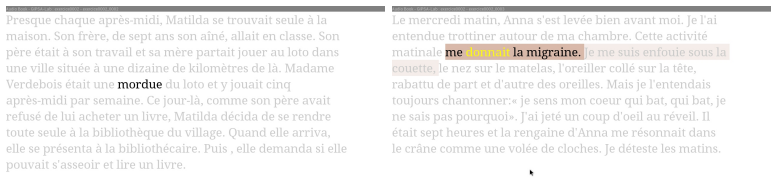

वण्व

Figure 1: Two Karaoke conditions. Left:word-only (WO); right: word \& breath group $(W B G)$. Note that, in both cases, the character (space or punctuation) associated with a pause is enlightened in red.

comprehension $[18,19]$. While maze is a curriculum test in the US, it is not commonly used with French pupils. In this test, the subject is given a text with one word in seven deleted and substituted with 3 proposals, including the correct word. The subject has 3 minutes to circle as many correct proposals as he can. We used an alternative maze test in which the text is entirely read aloud by the subject. The test is scored on both right answers and reading time [20]. This oral maze test (OMT) enables to assess both fluency and comprehension in a rapid single test $[21,22]$

\section{Experimental design}

\subsection{Protocol}

We contrast between two Karaoke conditions: word-only (WO) enlightenment vs. word \& breath group (WBG) enlightenment. Four texts of approximately one hundred words were chosen from books used in third grade by French teachers [23, 24]. The texts were rated of equal complexity in terms of average lexical frequencies and sentence lengths. Subjects were first presented with the objectives of the study (monitoring their breathing when reading) and the workflow, where we monitored speech and breathing patterns during a series of RwL, free and OMT readings of two texts among the four. RwL of each text was performed in one of the two conditions we wanted to contrast, Word Only(WO) vs. Word and Breathing Group (WBG), in random order. Each session thus consisted in the following tasks:

- Screening their non-verbal IQ (Raven test [25]) and reading age (Alouette reading test [26]).

- Familiarization with the Karaoke display using a sample text with WBG presentation.

- For each text: RwL condition, OMT, free aloud reading

\subsection{Subjects}

The protocol was submitted and approved by the director of the departmental (Isère) services from the French Ministry of Education. 51 3rd graders ( $8.6 \pm 0.3$ years) from 3 classes with volunteer teachers participated to the experiments with the written authorization of their parents: 1 class from a small rural school (15 pupils), 1 class from a big rural school (26 pupils), 1 class from a small urban school (10 pupils) in the Grenoble area.

The average score to the RAVEN [25] test $(35.3 \pm 7.6)$ corresponds to the group's age ( 35 at 8 years). The average reading level ( $8.3 \pm 1.1$ years) estimated via the Alouette test [26] also corresponds to the mean group age. It is to be noted that there are 2 skilled readers among the group (reading age $=12.25$, RAVEN $=49$ ) as shown in Figure 2. 

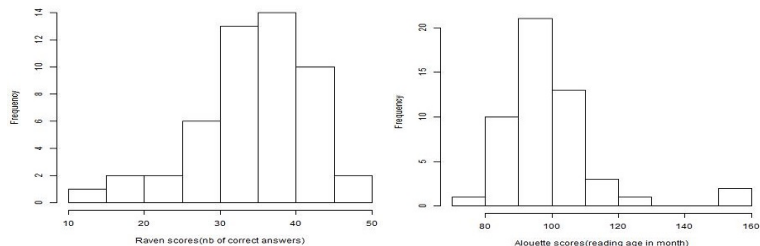

Figure 2: Subjects' distribution in the Raven and Alouette tests. The results to both tests are poorly correlated $\left(R^{2}=0.022\right)$

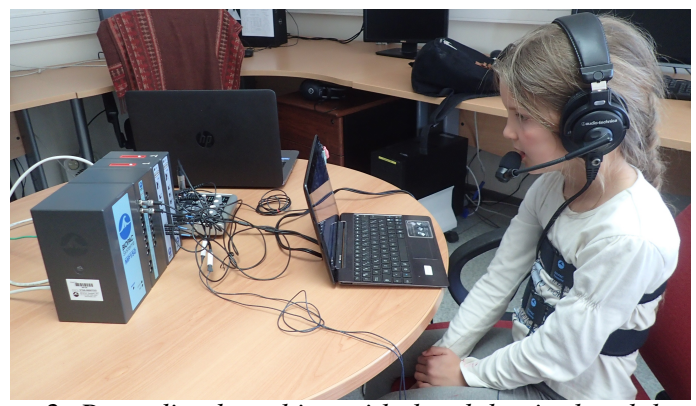

Figure 3: Recording breathing with the abdominal and thoracic respiratory belts and voice with the headset of a pupil reading the Karaoke.

\subsection{Experimental setting}

The typical experimental setting is shown in Figure 3. The RAKE (Reading Assistance by KaraokE) system provides the synchronous audiovisual display of texts read aloud by the first author at an average rate of 99 words/mn and an articulation rate of 3.6 syllables/s. RAKE is running on a ASUS TFT 100 tablet. Subjects wear a Audio-Technica BPHS1 stereo headset, including both headphones and a cardioid dynamic microphone. Thanks to a mixing board (Micline mixer Mackie 402-VL23), the master sound from the tablet is sent to both the headphones and the Biopac MP150. The latter also collects the respiratory patterns by means of two RSP100C belts placed on the abdomen and the thorax of the subject and his/her voice, recorded via the headset microphone.

\subsection{Data processing and labeling}

Audio signals were automatically aligned with text using context-independent HMM trained on children data. The si-

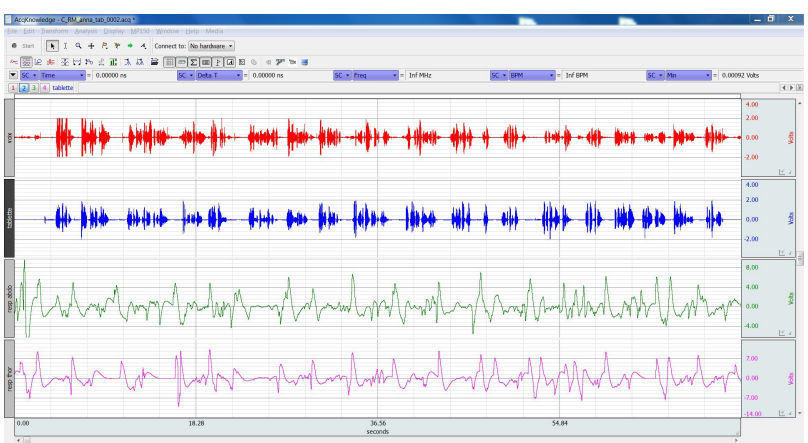

Figure 4: Acquisition of the 4 signals with the BIOPAC $C^{\circledR}$ system. Channel 1 is the children voice recorded by the headset microphone, channel 2 is the master voice output by the tablet delivered via the headphones, channels $3 \& 4$ are the monitored abdominal vs. thoracic breathing signals.
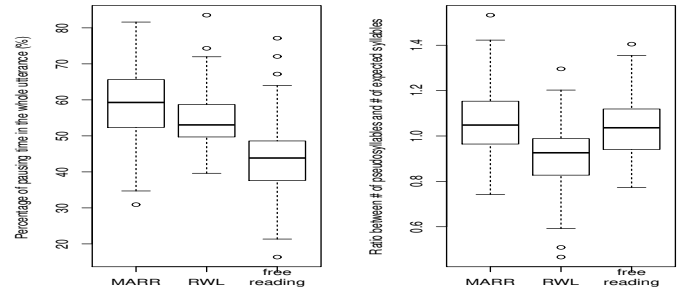

Figure 5: Comparing rhythm of RwL, OMT and free reading. Left: percentage of silence in the utterance. Right: ratio between pseudo-syllables and expected syllables. We used Praat [27] for locating the silences and AuToBI [28] for finding the pseudo-syllables.

lence model was especially designed for coping with breath noises, coughs and sniffs. These phonetic alignments were further hand-corrected using Praat because of the large variability on the data quality between subjects. Onsets of phonation were complemented with annotations regarding the time delay between these events and the neighboring inhalation onsets. Note that these delays are occasionally negative, i.e. several phonations start with ingressive sounds performed during inhalation.

\subsection{Analysis}

The objective was to test the shadowing of voice and breathing between the student and the karaoke tutor and the text comprehension in both conditions (WO vs WBG). We first compared the pauses and ratio between pseudo-syllables and expected syllables in the three tasks (RWL, OMT and free reading) using Praat and AuToBI. In order to globally characterize the close-shadowing performance, we computed the optimal delay between the children (channel 1) and master (channel 2) by cross-correlating the short-term energy profiles. The breathing was characterized by the inhalation-to-phonation delay. A t-test was performed to compare this delay in both condition (WO vs.WBG). The delay between children and master's inhalation was also measured and compared using a t-test. Finally, during OMT, we noted the number of correct answers to the 3 alternatives and the time needed to complete the task. We used an anova to estimate the influence of the condition (WO ws WBG), reading level (Alouette), non-verbal-IQ (Raven) and text, on the OMT scores.

\section{Results}

\subsection{Comparing RwL, OMT and free reading}

Figure 5 contrasts the performance of the readers in the different activities. Due to the difficulty of the task, OMT requires more frequent and lengthy pauses: the total pause duration is 59\% for OMT compared to $55 \%$ and $44 \%$ for RwL and free reading. These pairwise comparisons show that the total pause durations significantly differs along all the conditions $(p<0.001)$. As expected free reading is faster than RwL since Karaoke forces the reader to constitute consistent breathing groups, causing the overall pause duration to increase. There is a higher number of pseudosyllables in free reading and OMT compared to RwL: the ratios between the number of pseudosyllables and the number of expected syllables in the read text are 1.06, 1.04 vs 0.91 . Differences between the distribution of RwL ratios vs. free reading and OMT are statistically significant at $p_{i} 0.001$. There is no sig- 

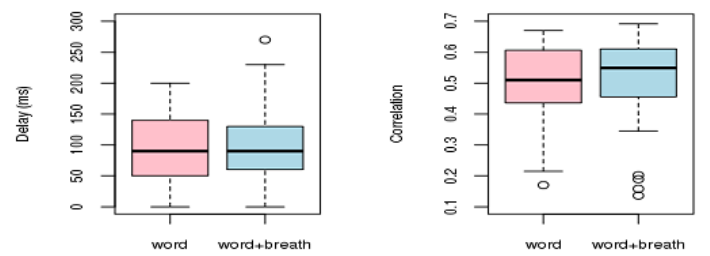

Figure 6: Close-shadowing results. Distributions of the shadowing delays (left) and correlation coefficients (right) according to the Karaoke condition.
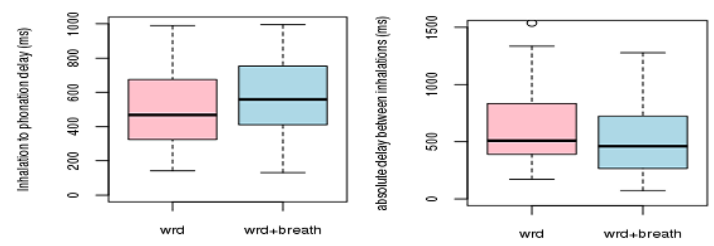

Figure 7: Distributions of the children' inhalation-to-phonation delays (left) and of delays between children and master inhalations (right) according to the Karaoke condition.

nificant differences between free reading and OMT ( $p>0.4)$. Note that the value of the ratio for free reading and OMT is higher than 1. This is due to the high number of disfluences found in the readings. The RwL activity reduces the degree of syllabification with a ratio value lower to 1 , indicating a benefit for automaticity.

\subsection{Close-shadowing performance}

Figure 6 displays the distributions of the delays between master and children and the associated correlation coefficients according to the Karaoke condition. Note that the average shadowing delay is close to $100 \mathrm{~ms}$, which is a bit higher than what Bailly [29] observed for adults reading a well-known passage. While correlation coefficients seem to be higher in the WBG condition, none of the observed differences are statistically significant.

\subsection{Impact of the enlightening condition on breathing}

Figure 7-left shows the distributions of the inhalation-tophonation delays according to the Karaoke condition. The condition have a strong impact $\left(p<10^{-15}\right)$ on this feature: children anticipate inhalation much earlier in the WBG condition because of the cueing of upcoming breathing opportunities/dates by the enhanced Karaoke. Five pupils outline the distributions, mainly because of their unstructured phonations that do not provide reliable landmarks for relating phonation onsets to corresponding inhalations. Note that we get an average of $500 \mathrm{~ms}$. This should be compared to the $350 \mathrm{~ms}$ delay usually performed by adults within paragraphs [7]. We expect that the maturing of the synchronization between breathing and speech production will evolve towards a just-in-time performance, i.e. end of inhalation coincides with start of phonation. Moreover delays between children and master's inhalations differ significantly between the 2 conditions (cf. right side of Figure 7). The delay for WBG condition is significantly lower $(p<0.008)$ showing that children tends to have a breathing pattern closer to the tutor's one than in WO condition. It is to be noted that the pupils outlining the distributions are, in this case, the best readers (Alouette score $>10$ ). Their breath groups are meaningful
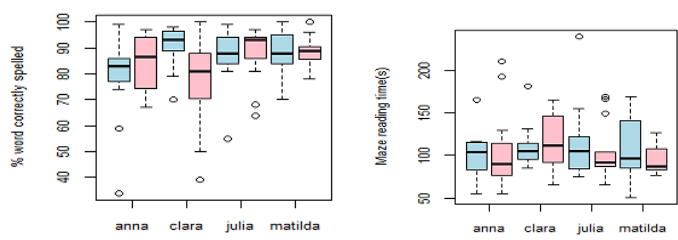

Figure 8: Comprehension results. Distribution of the percentage of words correctly spelled and oral maze time for each text in both karaoke conditions : WBG in blue, and WO in pink

but also longer than the tutor's ones which are regulated to help poor readers with small breath groups.

\subsection{Impact of the enlightening condition on comprehension}

The OMT performance measurements show a significant difference between the 2 conditions. Contrary to our expectations, the scores are a little higher in the WO condition. However if the number correct answers is significantly better for the WO conditions, the time-to-complete is significantly lower for the WBG condition. To summarize, they read faster but make more mistakes in WBG condition. Reading level and the number of correct answer to the Raven score also have a significant impact on the score and the time $(p<0.05)$. We also had a look at the number of words read and the number of words correctly spelled during the Karaoke. The ANOVA shows also a significant influence of the reading level (Alouette score) $(p<0.001)$ on both number of words correctly spelled, and on the number of words read. It is to be noted that for all those analysis, as showed in Figure 8, the text "Clara" - whose average lexical frequency is sightly lower than the other three - has significantly different results compared to the other 3 .

\section{Discussion}

Several experimental variables are expected to impact the subjects' performance and the acceptability of the RAKE system: the delay between the acoustic onset of a word and its enlightening is set here to zero. We have however observed that adult readers prefer an anticipatory enlightening about $300 \mathrm{~ms}$ before its spelling. This variable should in some way mirror the complex subject-specific patterning of the coordinations between gaze and speech production. We will explore the possibility for subjects to adjust this delay. The corresponding psychometric procedure is rather tricky to set-up for children. Another way to increase the acceptability is to adapt the reading speed of the tutor to the fluency of the learner. In fact, several children didn't manage to follow correctly the Karaoke because it was too fast. We will then explore the possibility for the readers to adjust the reading speed to be comfortable. Pauses are also enlightened with a red marker that presently lights up in red and gradually vanishes to white as a function of relative elapsed duration. This certainly favors the anticipatory inhalation strategy observed in the WBG condition. We will study the impact of the enlightening profile on the breathing pattern.

The number of word correctly spelled during the Karaoke, the OMT scores are impacted by the text complexity and the children's reading level. We can hypothesize that the impact of the Karaoke condition is different regarding the reading level. Good readers cap in the reading and comprehension task, while the struggling readers have difficulties following the Karaoke, impacting both breath patterns and comprehension. We now plan to study the impact of Karaoke condition for the different 
reading levels.

As the results shows a difference in pauses and breathing between the 2 conditions, it could be interesting now to have a look at the pitch and F0, to see if the breath group enlightening has also an impact on prosody.

In this study we tested the comprehension after only one text reading. By increasing the number of Karaoke reading - i.e. with repetitive reading [30] - we may increase the difference between the two conditions.

\section{Conclusions}

Our project aims at enhancing fluency in young readers by introducing a Karaoke that both enlightens the current word and current/next breath groups. The RwL task is supposed to improve their prosody and comprehension skills. In this first study, we tested two different enlightenment conditions: word only (WO) vs. word and breath groups (WBG) on 51 3rd grade children. We show that WBG has a significant impact on breathing patterns and fluency (less pauses and less pseudo-syllables). The impact on text comprehension is however not significant.

We will carry on characterizing the children' performances, notably the free readings. Detailed analysis of segmental and prosodic patterns will be conducted to further examine the impact of the RwL condition on close-shadowing and further autonomous reading. One exposure is of course not sufficient: we will expect repeated RwL to improve over the sole repeated autonomous reading [31].

\section{Acknowledgements}

This work is supported by the e-FRAN project Fluence, sponsored by the "Investissements d'avenir" program.

\section{References}

[1] Z. Breznitz, Fluency in reading: Synchronization of processes Routledge, 2006.

[2] T. V. Rasinski, "Assessing reading fluency," Pacific Resources for Education and Learning (PREL), 2004.

[3] D. Bolinger and D. L. M. Bolinger, Intonation and its uses: Melody in grammar and discourse. Stanford University Press, 1989

[4] M.-S. Arcand, E. Dion, L. Lemire-Théberge, M.-H. Guay, A. Barrette, V. Gagnon, P.-O. Caron, and D. Fuchs, "Segmenting texts into meaningful word groups: Beginning readers prosody and comprehension," Scientific Studies of Reading, vol. 18, no. 3, pp. 208-223, 2014.

[5] M. Álvarez-Cañizo, P. Suárez-Coalla, and F. Cuetos, "The role of reading fluency in childrens text comprehension," Frontiers in psychology, vol. 6, 2015.

[6] P. J. Schwanenflugel, A. M. Hamilton, M. R. Kuhn, J. M. Wisenbaker, and S. A. Stahl, "Becoming a fluent reader: reading skill and prosodic features in the oral reading of young readers." Journal of educational psychology, vol. 96, no. 1, p. 119, 2004

[7] G. Bailly and C. Gouvernayre, "Pauses and respiratory markers of the structure of book reading," in InterSpeech, 2012, pp. 2218 2221.

[8] F. Grosjean and M. Collins, "Breathing, pausing and reading," Phonetica, vol. 36, no. 2, pp. 98-114, 1979.

[9] M. Lalain, T. Legou, C. Fauth, F. Hirsch, and I. Didirkova, "Que disent nos silences? apport des donnes acoustiques, articulatoires et physiologiques pour létude des pauses silencieuses," in Journes d'Etudes sur la Parole (JEP), 2016, pp. 563-570.

[10] T. V. Rasinski, "Effects of repeated reading and listening-whilereading on reading fluency," The Journal of Educational Re search, vol. 83, no. 3, pp. 147-151, 1990.
[11] W. van Bon, L. M. Boksebeld, T. Font Freide, and A. van den Hurk, "A comparison of three methods of reading-whilelistening," Journal of Learning Disabilities, vol. 24, no. 8, pp. 471-476, 1991.

[12] M. C. Biggs, S. P. Homan, R. Dedrick, V. Minick, and T. Rasinski, "Using an interactive singing software program: A comparative study of struggling middle school readers," Reading Psychology, vol. 29, no. 3, pp. 195-213, 2008.

[13] E. Gerbier, G. Bailly, and M.-L. Bosse, "Using karaoke to enhance reading while listening: impact on word memorization and eye movements," in Speech and Language Technology for Education (SLaTE), 2015, pp. 59-64.

[14] A. Stenton, "Can simultaneous reading and listening improve speech perception and production? an examination of recent feedback on the swans authoring system," Procedia-Social and Behavioral Sciences, vol. 34, pp. 219-225, 2012.

[15] G. Bailly, A. Rochet-Capellan, and C. Vilain, "Adaptation of respiratory patterns in collaborative reading," in Interspeech, 2013, pp. 1653-1657.

[16] Y. Kusumoto, "Exploring the effects of shadowing on prosody," in Prague, Czech Republic May 21-23, 2015, 2015, pp. 82-85.

[17] X. Yin and H. Yu, "Research of the breathing characteristics when reading short song-poems," in Audio, Language and Image Processing (ICALIP), 2014 International Conference on. IEEE, 2014, pp. 429-433.

[18] L. S. Fuchs and D. Fuchs, "Identifying a measure for monitoring student reading progress," School Psychology Review, vol. 21, no. 1 , pp. 45-58, 1992.

[19] H. I. Wiley and S. L. Deno, "Oral reading and maze measures as predictors of success for English learners on a state standards assessment," Remedial and Special Education, vol. 26, no. 4, pp. 207-214, 2005.

[20] A. D. Hale, J. B. Henning, R. O. Hawkins, W. Sheeley, L. Shoemaker, J. R. Reynolds, and C. Moch, "Reading assessment methods for middle-school students: An investigation of reading comprehension rate and Maze accurate response rate," Psychology in the Schools, vol. 48, no. 1, pp. 28-36, Jan. 2011. [Online]. Available: http://doi.wiley.com/10.1002/pits.20544

[21] S. J. McCane-Bowling, A. D. Strait, P. E. Guess, J. R. Wiedo, and E. Muncie, "The utility of maze accurate response rate in assessing reading comprehension in upper elementary and middle school students," Psychology in the Schools, vol. 51, no. 8, pp. 789-800, Sep. 2014

[22] A. D. Hale, R. O. Hawkins, W. Sheeley, J. R. Reynolds, S. Jenkins, A. J. Schmitt, and D. A. Martin, "An investigation of silent versus aloud reading comprehension of elementary students using maze assessment procedures," Psychology in the Schools, vol. 48, no. 1, pp. 4-13, 2011.

[23] R. Dahl, Matilda. Random House, 2002.

[24] M. Desplechin, Verte. École des loisirs, 2014.

[25] J. C. Raven et al., Raven's progressive matrices. Oxford Psychologists Press Oxford, 1998.

[26] P. Lefavrais, Manuel du test de l'Alouette: test d'analyse de la lecture et de la dyslexie. Éditions du Centre de psychologie appliquée, 1967

[27] P. P. G. Boersma et al., "Praat, a system for doing phonetics by computer," Glot international, vol. 5, 2002.

[28] A. Rosenberg, "Autobi-a tool for automatic tobi annotation." in Interspeech, 2010, pp. 146-149.

[29] G. Bailly, "Close shadowing natural versus synthetic speech," International Journal of Speech Technology, vol. 6, no. 1, pp. 11-19, 2003.

[30] W. J. Therrien, J. F. Kirk, and S. Woods-Groves, "Comparison of a reading fluency intervention with and without passage repetition on reading achievement," Remedial and Special Education, vol. 33, no. 5, pp. 309-319, 2012.

[31] A. C. Chang and S. Millett, "Improving reading rates and comprehension through timed repeated reading," Reading in a Foreign Language, vol. 25, no. 2, p. 126, 2013. 